\title{
THE CLINICAL IMPLICATION OF PERIOPERATIVE D-DIMER MONITORING IN OPEN BILIARY SURGERY FOR OBSTRUCTIVE JAUNDICE
}

\author{
Dimitar Tonev ${ }^{1}$, Nina Shachiri ${ }^{2}$
}

\author{
'National Multiproffle Transport Hospital 'Tsar Boris III', Department of Anaesthesiology \& Intensive Care, \\ Sofia, Bulgaria \\ ${ }^{2}$ Multiprofile Hospital for Active Treatment, Department of Anaesthesiology \& Intensive Care, \\ Mezdra, Bulgaria
}

\section{INTRODUCTION AND AIM}

Elevated D-dimer levels reflect the systemic activation of blood coagulation towards hypercoagulation and/or hyperfibrinolysis. In patients (pts) operated on for obstructive jaundice (OJ) most of triggering factors of coagulation are present, such as systemic biliary inflammatory response, malignancy, surgical trauma [1,2]. Little is known about the pattern and significance of D-dimer changes after surgery for OJ, which is the aim of our study.

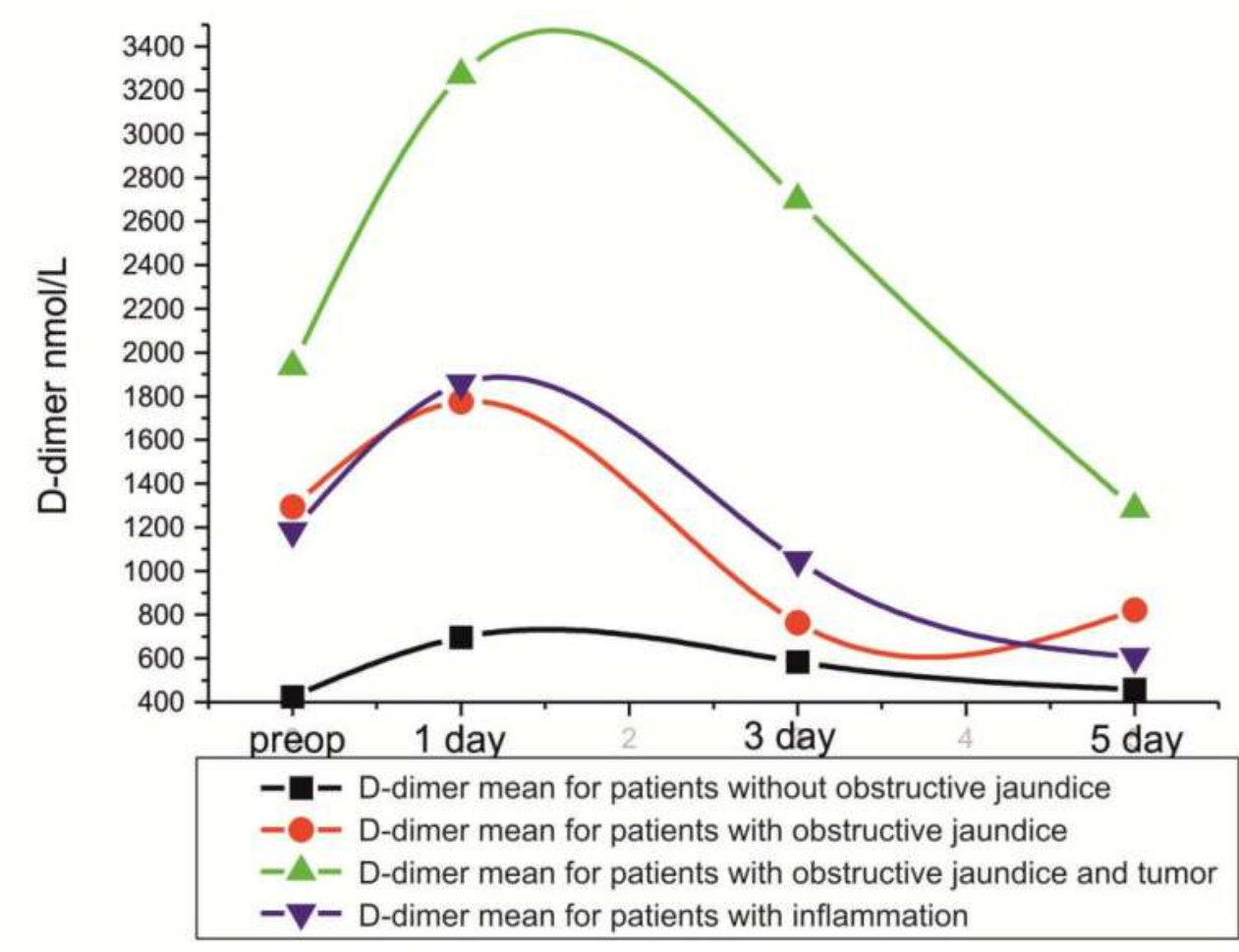

Figure 1. Perioperative mean values of D-dimer levels, betweengroups differences (groups A,C,D: p>0,05; group B: $p=0,0018$ One-Way ANOVA)

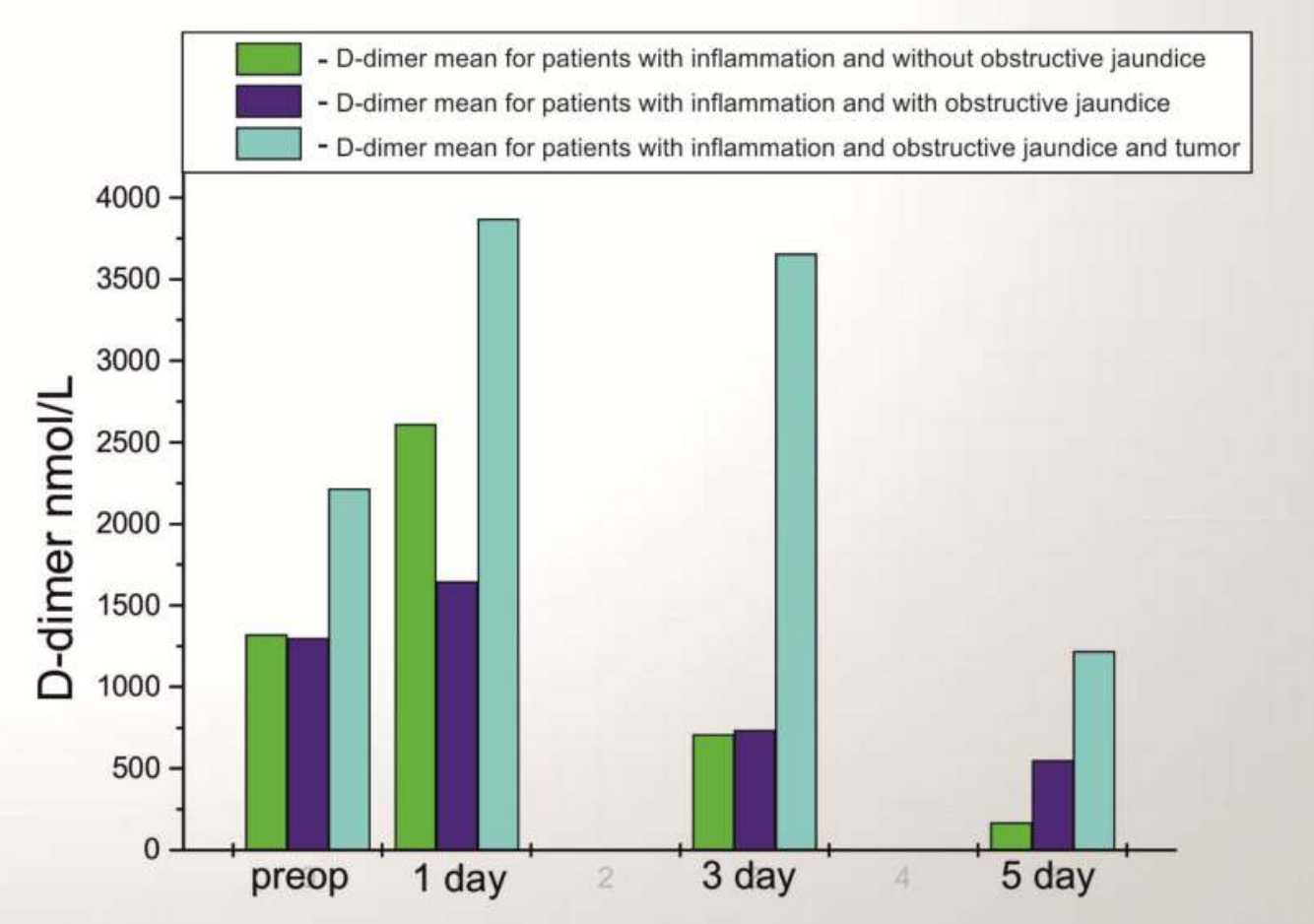

Figure 2. Perioperative mean values of D-dimer levels, withingroup differences (group D, subgroups with $\mathrm{OJ}: \mathbf{p}=\mathbf{0 , 0 0 3}$ One-Way ANOVA)

\section{References}

1. Papadopoulos $\mathrm{V}$, et al. Haemostasis impairment in patients with obstructive jaundice. J Gastrointest Liver Dis 2007; 16(2): 177-186

2. Shachiri N, et al. Hemostasiologic changes during hepatobiliary surgery in patients with obstructive jaundice: pathophysiology and clinical considerations. Internet J Anesthesiol 2010; 28(1)

3. Wada H, et al. Diagnosis and treatment of disseminated intravascular coagulation (DIC) according to four DIC guidelines. J Intensive Care 2014; 2:15

Correspondence to: Dimitar Tonev, $M D, P h D$, associate professor,

e-mail: tonev.md.phd@gmail.com

\section{MATERIALS AND METHODS}

One hundred and five consecutive adult patients undergoing open biliary surgery were included in a prospective, observational, descriptive study and were stratified as follows: with malignant OJ (group $\mathrm{A}, \mathrm{n}=36$ ), with benign OJ (group $\mathrm{B}, \mathrm{n}=39$ ), without OJ (group $\mathrm{C}, \mathrm{n}=30$ ) and with biliary inflammation (a casemix from groups mentioned above, group $\mathrm{D}, \mathrm{n}=39$ ). Plasma and whole blood samples were collected preoperatively and then on 1,3 and 5 postoperative days. D-dimer (normal range $0-500 \mathrm{nmol} / \mathrm{l}$ ) as well as PT, aPTT, antiplasmin, plasminogen, AT III, F XIII, prothrombin fragment $\mathrm{F} 1+2$ were measured using conventional assays, ELISE, and automated coagulation analyzer "STA Compact". The between-groups comparisons and multiple correlations with total bilirubin (i.e. with $\mathrm{OJ}$ ) and the other haemostatic parameters were calculated using OneWay ANOVA and stepwise multiple regression, respectively, at $\alpha=0.05$. Patients in groups $\mathrm{A}, \mathrm{B}$ and $\mathrm{D}$ received only postoperative LMWH thromboprophylaxis.

Table 1. Multiple correlations among perioperative D-dimer levels (dependent variable) and PT, antiplasmin, AT III, F 1+2 (factor variables $)(p<0,01$, stepwise multiple regression)

\begin{tabular}{|l|l|c|c|}
\hline Groups & \multicolumn{1}{|c|}{ Haemostatic parameters } & $\begin{array}{c}\text { R Square } \\
\left(\mathbf{R}^{2}\right)\end{array}$ & Std.Error \\
\hline Group A & Preoperative: D-dimer/Antiplasmin/F1+2 & 0,544 & 792,249 \\
\hline Group B & $\begin{array}{l}\text { Preoperative: D-dimer/AT III/F1+2 } \\
\text { 1 day: D-dimer/AT III/Antiplasmin }\end{array}$ & 0,506 & 708,416 \\
\hline Group C & 3 day: D-dimer/ PT/Antiplasmin/AT III & 0,445 & 1502,071 \\
\hline
\end{tabular}

\section{RESULTS AND DISCUSSION}

In groups A, B and D, there were abnormal increases of D-dimer levels preoperatively, with a peak at $1^{\text {st }}$ postoperative day and subsequent decreases (without reaching normal range) at $3^{\text {rd }}$ and at $5^{\text {th }}$ postoperative days, with the statistical significance only in group B (fig.1). Compared with group $\mathrm{C}$, the changes were the greatest in group A, followed by group D and group B (fig.1). In the presence of inflammation, the greatest increase of D-dimer levels was observed in group $\mathrm{A}$ as well (fig.2). There were moderate significant correlation $(0,3<\mathrm{R}<0,7)$ among perioperative D-dimer and PT, antiplasmin, AT III, F1+2 changes (stepwise multiple regression, tabl.1) as well as among preoperative D-dimer and PT, aPTT, F XIII, antiplasmin, plasminogen, AT III, F1+2 ones (linear regression). There were no cases with clinically overt massive bleeding and thromboembolic events perioperatively.

\section{CONCLUSIONS}

The changes in D-dimer levels are not isolated, but go with the changes in other haemostasis parameters (such as PT, aPTT, antiplasmin, AT III, F XIII, prothrombin fragment F1+2). In cases of preoperative elevated D-dimer levels and more than one abnormalities in the above laboratory tests, it could be assumed non-symptomatic DIC or pre-DIC and considered the implementation of Heparin/LMWH preoperatively as well [3]. 